\title{
PPM Kelurahan Teratai Kecamatan Muara Bulian dalam upaya pemanfaatan lahan pekarangan untuk peningkatan produksi dan kualitas tanaman jahe merah
}

\author{
Nerty Soverda*, Zulkifli Alamsyah, Elly Indraswari, Yulia Alia, dan \\ Neliyati
}

Fakultas Pertanian, Universitas Jambi

*nsoverda@yahoo.com

\begin{abstract}
One of the efforts to make efficient use of yard is by planting with plants that are used to meet the needs of themselves and the needs of others. In addition, to make efficient use of land and yard will be well maintained, beautiful and also increase household income. In Teratai village, Muara Bulian sub-district, there is agroindustry based on farmer group which has the healthy drink with the red ginger raw material. They produce these healthy drinks by using raw materials ordered from other regions. This makes agroindustry highly dependent on the supply of others to meet the needs of these raw materials. In this devotional activity carried out demonstration area on the farmyard yard where the Team Dedication as a companion. Through demonstration the farmers' area gets direct guidance from the Community Services Team, seeing and practicing every material given in accordance with the stages of plant development. In this way, it is expected to transfer knowledge and technology effectively from universities to the community. Thus, it is expected to increase the knowledge and skills of farmers in the cultivation of red ginger plants as yard plants, especially ginger farmers in the village of Teratai and generally red ginger farmers in Muara Jambi Regency.
\end{abstract}

\begin{abstract}
Abstrak Salah satu upaya untuk mengefisienkan penggunaan lahan pekarangan adalah dengan menanaminya dengan tanaman yang bermanfaat untuk memenuhi kebutuhan sendiri maupun kebutuhan orang lain. Selain itu, untuk mengefisienkan pemanfaatan lahan dan lahan pekarangan akan terawat, indah dan juga menambah pendapatan rumah tangga. Di desa Teratai kecamatan Muara Bulian terdapat agroindustri berbasis kelompok tani yang mengusahakan minuman kesehatan dengan bahan baku jahe merah. Mereka memproduksi minuman kesehatan ini dengan menggunakan bahan baku yang dipesan dari daerah lain. Hal ini membuat agroindustri sangat tergantung dari pasokan orang lain untuk memenuhi kebutuhan bahan baku tersebut. Pada kegiatan pengabdian ini dilaksanakan demonstrasi area pada lahan pekarangan petani dimana Tim Pengabdian sebagai pendamping. Melalui demontrasi area petani mendapatkan bimbingan langsung oleh Tim Pengabdian, melihat dan mempraktekkan setiap materi yang diberikan sesuai dengan tahapan perkembangan tanaman. Dengan cara seperti ini diharapkan terjadi transfer pengetahuan dan teknologi yang efektif dari perguruan tinggi kepada masyarakat. Dengan demikian, diharapkan terjadi peningkatan pengetahuan dan ketrampilan petani dalam pengusahaan tanaman jahe merah sebagai tanaman pekarangan, khususnya petani jahe di desa Teratai dan umumnya petani jahe merah di Kabupaten Muara Jambi.
\end{abstract}

Keywords: utilization of yard; production; red ginger

\section{OPEN ACCESS}

Citation: Soverda, N., Z. Alamsyah, E. Indraswari, Y. Alia, dan Neliyati. 2018. PPM Kelurahan Teratai Kecamatan Muara Bulian dalam upaya pemanfaatan lahan pekarangan untuk peningkatan produksi dan kualitas tanaman jahe merah. Riau Journal of Empowerment 1(1): 45-49 https://doi.org/10.31258/raje.1.1.6

Received: 2018-05-16, Revised: 2018-08-12, Accepted: 2018-08-15

Language: Bahasa Indonesia (id)

C 2018 Soverda et al. The article by Author(s) is licensed under a Creative Commons Attribution 4.0 International License. This license permits unrestricted use, distribution, and reproduction in any medium, provided the original author and source are credited. 


\section{PENDAHULUAN}

Jahe (Zingiber Officinale) adalah merupakan tumbuhan rimpang yang banyak dimanfaatkan untuk pelengkap makanan atau bumbu masakan dan juga sebagai obat. Rimpang tanaman jahe berbentuk jari yang bergelembung pada ruas-ruas tengahnya. Jahe merah mempunyai rasa yang khas yaitu pedas dan menghangatkan. Rasa pedas dan menghangatkan itu dikarenakan adanya senyawa keton yang disebut Zingeron.

Tanaman jahe merah adalah tanaman yang termasuk tanaman jahe-jahean yang mempunyai umbi. Tanaman ini merupakan tanaman herbal yang sudah dikenal dan dimanfaatkan sejak dahulu oleh masyarakat Indonesia. Pada tanaman ini yang banyak dimanfaatkan adalah rimpangnya karena pada bagian rimpang ini banyak mengandung senyawa alami yang berkhasiat buat kesehatan.

Tanaman jahe merah yang mempunyai nama latin Zingiber Officinale linn var rubrum rhizoma ini mengandung khasiat yang bermanfaat dan minim efek samping. Manfaat jahe merah ini antara lain adalah merangsang kekebalan tubuh, menguatkan hati (hepar), mencegah kemandulan, merangsang keluarnya ASI dan mencegahan pendarahan diluar haid [1].

Desa Teratai adalah salah satu desa di Kecamatan Muara Bulian yang mempunyai luas wilayah lebih kurang 1600 ha dengan jumlah dusun/RW adalah 3 dusun dan 23 RT. Jumlah penduduk sebanyak 5.404 orang dengan sebaran laki-laki sebanyak 4.302 orang dan wanita 1.102 orang. Pada desa ini terdapat satu kelompok tani yang anggotanya terdiri dari ibu-ibu anggota PKK sehingga kelompok taninya diberi nama kelompok tani PKK RT 15. Beberapa orang dari anggota kelompok tani ini mempunyai usaha sampingan dengan mengusahakan usaha home industry. Ada yang menanam jamur tiram, keripik ubi, keripik pisang dan minuman kesehatan Jahe merah.

Salah satu anggota kelompok tani ada yang mengusahakan minuman kesehatan ini yang mereka beri nama "Bandrek Sari Jahe". Minuman kesehatan yang mereka usahakan ini menggunakan bahan baku jahe merah yang mereka pesan dari Jawa. Permintaan konsumen akan minuman "Bandrek Sari Jahe" ini makin hari makin meningkat. Makin banyaknya permintaan akan minuman kesehatan dari jahe merah yang mereka usahakan mengakibatkan mereka membutuhkan bahan baku yang lebih banyak. Petani berusaha memenuhi kebutuhan bahan baku ini melalui pemanfaatan pekarangan mereka. Namun petani dihadapi dengan beberapa kendala, antara lain keterbatasan pengetahuan mereka tentang cara yang efisien dalam pemanfaatan lahan pekarangan. Disamping itu petani terkendala dengan cara pembudidayaan tanaman jahe merah yang baik agar tanaman dapat tumbuh baik dengan produksi tinggi dan kualitas yang baik.

Peningkatan produksi jahe merah melalui pemanfaatan lahan pekarangan adalah merupakan salah satu usaha yang dapat dilakukan, khususnya di desa Teratai Kecamatan Muara Bulian, Jambi. Pemanfaatan lahan pekarangan disekitar rumah merupakan salah satu upaya yang dapat dilakukan dalam mengefisiensikan lahan dan pemanfaatan pekarangan dengan menanam tanaman jahe merah dengan menggunakan tempat-tempat atau karung yang diberi media yang sesuai dengan lingkungan tumbuh yang baik dan sesuai untuk tanaman jahe merah. Petani akan memperoleh beberapa keuntungan dari usaha menanam jahe merah disekitar rumah mereka. Apabila pemanfaatan pekarangan ini dapat mereka laksanakan, maka ketergantungan mereka akan bahan baku dari Jawa dapat diatasi.

Salah satu usaha untuk dapat mengembangkan tanaman jahe merah di kelurahan Teratai ini adalah melalui pemanfaatan lahan pekarangan, seperti dengan mengusahakan penanaman dalam pot-pot atau wadah-wadah yang dapat digunakan sebagai tempat media tanam. Selain itu, menurut menurut Wahyuni dkk [2], diperlukan adanya pemberian pupuk terutama pupuk organik dengan tujuan selain dapat menambah hara bagi tanaman jahe merah yang akan diusahakan, dapat pula menyumbangkan hara khusus untuk tanaman jahe merah yang diusahakan yang merupakan tanaman pokok, tanpa dipengaruhi oleh tanaman lain sekitar lingkungan tumbuhnya.

Selain hal tersebut diatas, untuk meningkatkan daya dukung lahan [3] diperlukan pula adanya suatu cara untuk meningkatkan kemampuan tanah dalam menyediakan unsur hara bagi 
tanaman Jahe. Selain itu, diharapkan pemberian kompos pada lahan kering jenis ultisol mampu meningkatkan pertumbuhan dan hasil pada tanaman.

\section{MASALAH}

Kelurahan Teratai yang terletak di Kecamatan Muara Bulian merupakan kelurahan yang mata pencarian utama masyarakatnya cukup beragam, namun sebagian besar mata pencarian masyarakat adalah bertani yaitu bertani karet. Disamping bertani, sebagian masyarakat ada yang mengusahakan usaha home industry sebagai penopang kehidupan keluarga. Di antara pengusaha home industry tersebut terdapat keluarga yang mengusahakan minuman kesehatan yang disebut dengan "Bandrek Sari Jahe". Minuman ini bahan bakunya terbuat dari Jahe merah.

Bahan baku jahe merah ini oleh masyarakat home industry di kelurahan Teratai ini didatangkan dari Jawa. Dengan demikian modal pembuatan minuman ini menjadi tinggi karena ongkos kirim yang mahal. Disamping itu, pemesanan bibit ke Jawa membutuhkan waktu cukup lama menanti datangnya pesananan bahan baku tersebut. Oleh karena itu, masyarakat pengusaha home industry tersebut berusaha juga untuk bisa menanam sendiri tanaman jahe merah disekitar perumahan mereka sebagai tanaman pekarangan.

Namun, pengembangan usaha tani jahe merah dilahan pekarangan sebagai tanaman obat memiliki beberapa kendala, antara lain yaitu: (1) Tanaman yang tumbuh di pekarangan sangat beragam. Keadaan ini akan mengakibatkan tanaman jahe merah yang tumbuh di sela-sela tanaman lain itu akan kesulitan untuk beradaptasi karena kompetisi yang tinggi terhadap cahaya matahari. Disamping itu, kemampuan tanaman jahe merah untuk beradaptasi terhadap kondisi tersebut akan ditentukan oleh kemampuannya untuk dapat melakukan proses fotosintesis secara normal. (2) Lahan-lahan pekarangan ini berpotensi untuk dikembangkan menjadi lahan produktif, namun demikian beberapa masalah yang berkaitan dengan agroekosistem harus diatasi, salah satunya adalah kondisi lahan yang terbatas dengan tumbuhan di pekarangan yang tumbuh sangat beragam. Keadaan ini membuat penanaman tanaman jahe merah sebagai tanaman obat tidak dapat diusahakan secara optimal.

Dari kondisi diatas ada beberapa hal penting yang perlu dicarikan solusi terhadap permasalahan yang dihadapi petani di lokasi pengabdian. Permasalahan pertama adalah kebutuhan baku Jahe merah yang makin meningkat dengan majunya usaha home industry yang mereka usahakan. Kedua, bahan baku jahe merah tidak dapat mereka usahakan sendiri, karena terbatasnya pengetahuan mereka akan bercocok tanam jahe merah. Ketiga, pengembangan tanaman dapat dilakukan sebagai tanaman pekarangan, namun karena lahan pekarangan terbatas dan tumbuhan beragam maka pertumbuhan jahe merah tidak dapat optimal.

\section{METODE}

Salah satu alternatif yang dapat dilakukan petani untuk mendapatkan pendapatan tambahan adalah dengan memanfaatkan potensi lahan disekitar rumah mereka dengan menanam tanaman sebagai tanaman pekarangan. Salah satu alternatif tanaman pekarangan yang dapat mereka usahakan adalah tanaman jahe merah. Tanaman jahe merah ini dapat mereka gunakan sebagai bahan baku usaha home industri yang mereka lakukan.

Ada beberapa keuntungan yang dapat diperoleh oleh masyarakat petani Kelurahan Teratai dari pemanfaatan lahan pekarangan ini, antara lain adalah: (1) mengoptimalkan pemanfaatan sumberdaya lahan pada pekarangan; (2) memproduksi sendiri pahan baku minuman kesehatan yang mereka usahakan; (3) pengalokasian tenaga kerja keluarga petani yang efektif dan efisien pada tanaman jahe merah dalam polybag; (4) meningkatkan pendapatan petani, dan; (5) memberikan kontribusi terhadap produksi jahe merah daerah.

Penanaman tanaman jahe merah di polybag sebagai tanaman pekarangan di Kelurahan Teratai Kecamatan Muara Bulian diawali dengan kegiatan penyuluhan dan pelatihan tentang teknik budidaya tanaman jahe merah kepada para petani. Pada kegiatan ini akan diberikan materi penyuluhan dan pelatihan mulai dari tahapan pengolahan tanah dan komposisi media sebelum dimasukkan ke polybag, pemupukan dan cara pembuatan pupuk organik dari 
sumberdaya yang tersedia secara lokal, perlindungan tanaman hingga panen dan penanganan paska panen.

Media penyuluhan dan pelatihan yang sangat efektif dalam kegiatan pengabdian ini adalah membangun demonstrasi area pada lahan petani dimana Tim Pengabdian sebagai pendamping dan petani jahe merah dapat langsung berinteraksi di lapangan. Melalui demontrasi area petani mendapatkan bimbingan langsung oleh Tim Pengabdian, melihat dan mempraktekkan setiap materi yang diberikan sesuai dengan tahapan perkembangan tanaman. Dengan cara seperti ini diharapkan terjadi transfer pengetahuan dan teknologi yang efektif dari perguruan tinggi kepada masyarakat. Dengan demikian diharapkan terjadi peningkatan pengetahuan dan ketrampilan petani dalam pengusahaan tanaman jahe merah dalam polybag sebagai tanaman pekarangan di lahan pekarangan kelompok tani, khususnya petani jahe merah di Kelurahan Teratai Kecamatan Muara Bulian.

Sebagai target akhir dari kegiatan pengabdian ini adalah terjadi peningkatan pendapatan petani dari teknologi yang diberikan diatas. Untuk meyakinkan petani mengenai peningkatan pendapatan ini maka diperlukan juga kegiatan penyuluhan dan bimbingan tentang pengelolaan administrasi usahatani terutama yang menyangkut pembukuan usahatani dan perhitungan sederhana mengenai analisis biaya dan pendapatan usahatani. Dengan demikian petani secara individual ataupun berkelompok dapat melakukan perhitungan-perhitungan untuk menguji bahwa teknologi yang dilaksanakan diatas secara ekonomi menguntungkan.

\section{PEMBAHASAN}

Sebelum pelaksanaan kegiatan, telah dilakukan peninjauan terhadap lokasi yang akan digunakan untuk kegiatan pengabdian pada bulan 3 Maret 2017. Lokasi yang ditinjau adalah lokasi yang sesuai dengan kriteria yang telah ditetapkan. Dari hasil survey maka pada tanggal 5 Maret 2017 disepakati pernyataan kerja sama dengan kelompok tani ditetapkan bahwa Desa Teratai yaitu pada Kelompok Wanita Tani RT 15 dengan ketua kelompoknya adalah Ibu Endang Sriwahyuni, SP. Desa Teratai ditetapkan sebagai lokasi untuk pembuatan demplot. Situasi saat dilakukan penetapan lokasi kegiatan dan kesepakatan dengan kelompok Tani Wanita RT 15 di Desa Teratai dapat dilihat pada Gambar 1.
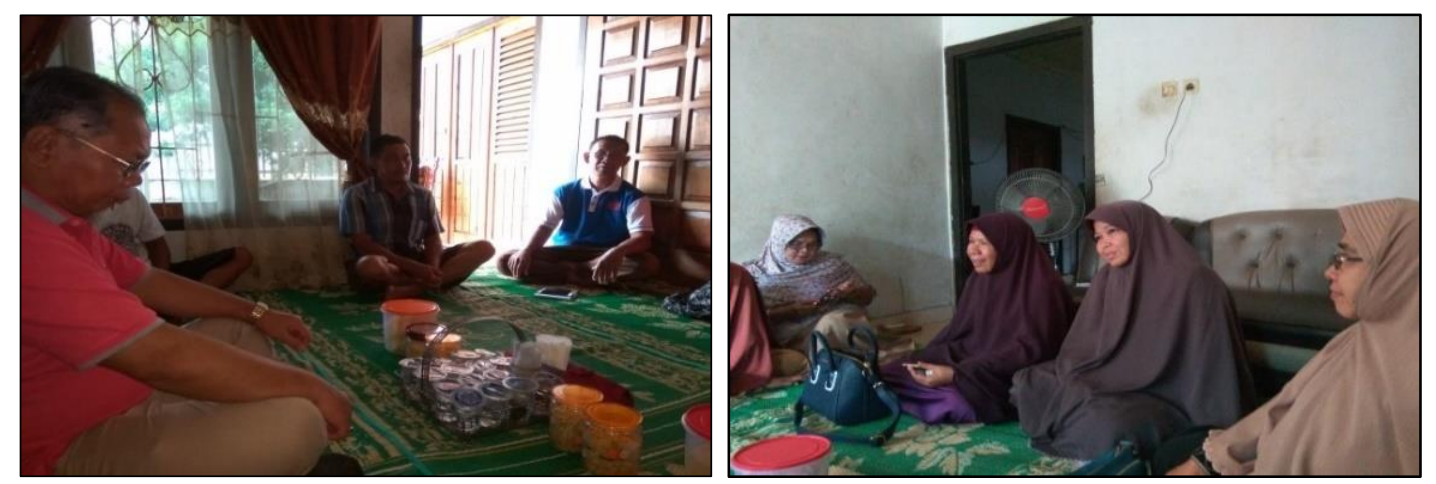

Gambar 1. Situasi saat penentuan lokasi dan diskusi dengan Kelompok Tani Wanita RT15 Desa Teratai Kecamatan Muara Bulian

\section{Sosialisasi, Penyuluhan dan Pengenalan Teknologi Yang Akan Diterapkan}

Pada bulan Mei 2017 telah dilakukan sosialisasi, penyuluhan dan pengenalan teknologi yang akan diterapkan. Kegiatan ini dilakukan di rumah ketua kelompok tani. Telah dijelaskan tentang keuntungan-keuntungan dari pemanfaatan lahan pekarangan, tepatnya tanaman jahe merah. Disamping lahan pekarangan dapat dimanfaatkan untuk penanaman tanaman jahe merah juga untuk menambah pendapatan petani, serta juga dapat menjaga kebersihan dan keindahan lahan dan lingkungan. 


\section{Pengolahan Tanah, Pengisian Polybag dan Penanaman}

Soverda dkk.

Setelah dilakukan sosialisasi dan penyuluhan tentang pemanfaatan lahan pekarangan melalui penanaman tanaman jahe merah dalam polybag maka dilakukan demonstrasi pembuatan campuran media. Kegiatan didahului dengan pengolahan media tanam dan pengisian polybag, dan melakukan penananam. Selanjutnya dilakukan pemeliharaan oleh petani yang termasuk dalam kelompok tani Wanita RT 15 di Desa Teratai Kecamatan Muara Bulian. Berikut dokumentasi kegiatan menyiapkan media tanam dan mengisi polybag yang dapat dilihat pada Gambar 2 dan Gambar 3.
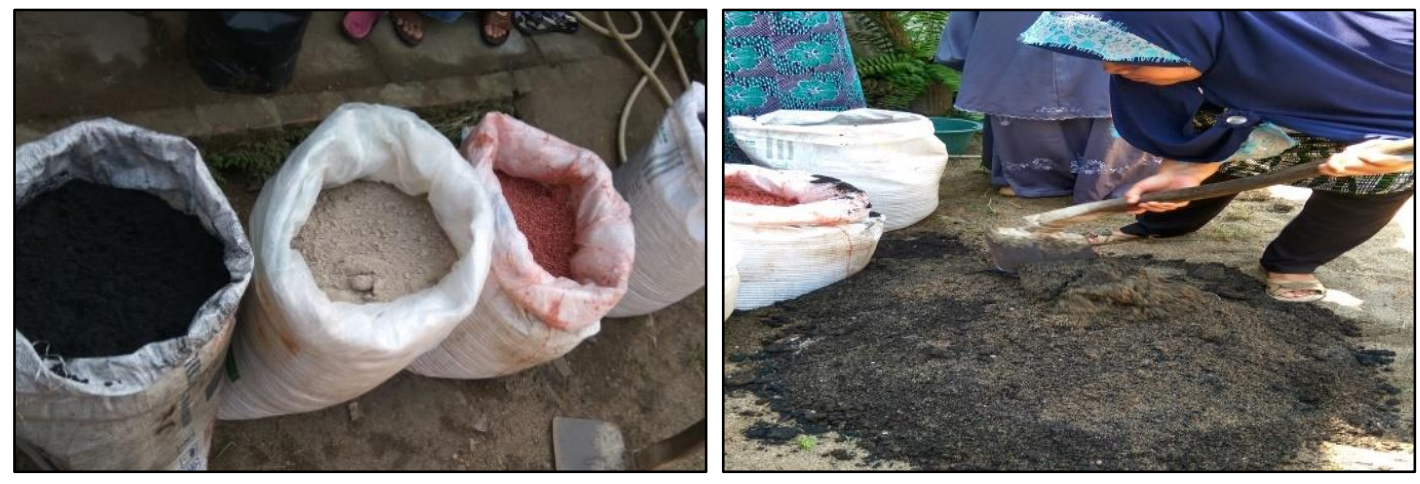

Gambar 2. Media tanam yang akan dicampur (kiri) dan pencampuran media tanam (kanan)
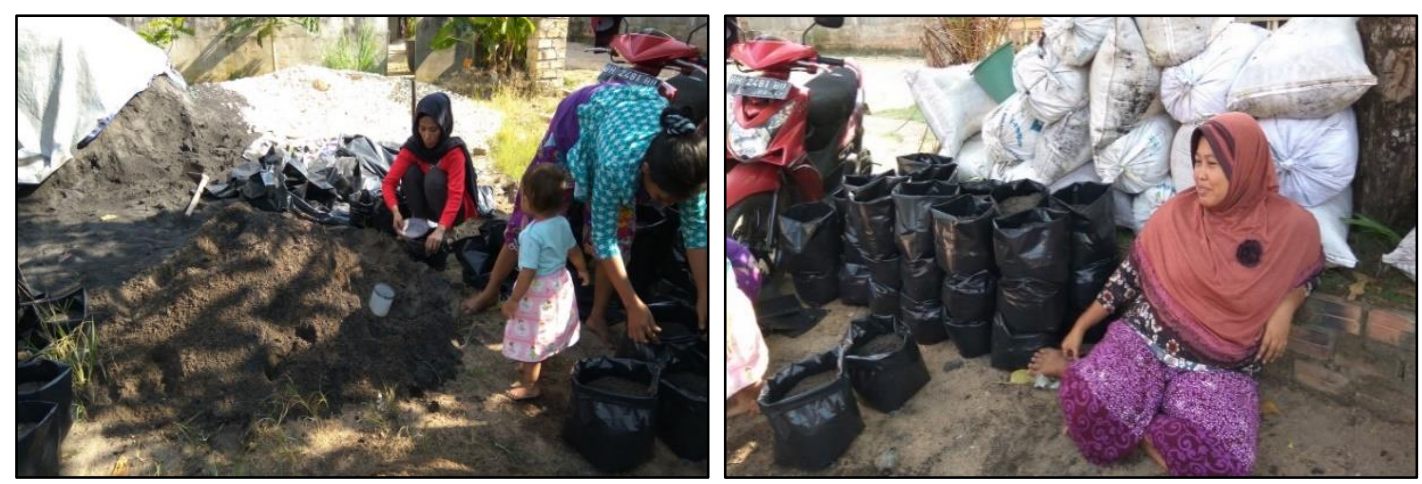

Gambar 3. Pengisian polybag (kiri) dan polybag yang telah siap untuk ditanami (kanan)

\section{KESIMPULAN}

Kegiatan-kegiatan yang telah dilakukan sampai saat artikel ini dibuat adalah kegiatan penyuluhan, pelatihan dan pendampingan yang meliputi penyuluhan tentang pemanfaatan lahan pekarangan, terutama dalam pemanfaatan pekarangan untuk penanaman tanaman jahe merah. Respon dari mitra sangat positif, di mana mitra memberikan antusias dan mau menerima inovasi teknologi yang diberikan serta memiliki minat yang tinggi dan bersedia untuk menerapkan teknologi yang diberikan dalam pemanfaatan pekarangan.

\section{Daftar Pustaka}

1. Hernani dan C. Winarti. 2014. Kandungan Bahan Aktif Jahe dan Pemanfaatannya dalam Bidang Kesehatan. Balai Besar Penelitian dan Pengembangan Pascapanen Pertanian. Bogor.

2. Wahyuni, A. Barus, dan Syukri. 2013. Respon Pertumbuhan Jahe Merah (Zingiber officinale Rosc.) terhadap Pemberian Naungan dan Beberapa Teknik Bertanam. Jurnal Online Agroekoteknologi Vol.1, No.4, September 2013. ISSN No. 2337- 6597

3. Wiroatmodjo, J.L., Anas, dan Sugihmoro. 1988. Penggunaan Effective Microorganisms 4 (EM4) dan Bahan Organik Terhadap Pertumbuhan dan Produksi Jahe (Zingiber Officinale Rocs.) Jenis Badak. Buletin Peragi IV (1-2): 22-31. 